\title{
Compliments and Identity Construction in East-West Intercultural EFL Communication
}

\author{
Hiroko Itakura
}

\begin{abstract}
This paper explores identity construction in the hitherto little-researched context of intercultural communication between speakers of English as a foreign language (EFL) in a study-abroad context. In a case study of naturalistic conversations between a Chinese male and a Swedish male, the paper examines how compliments were used similarly or differently between two speakers. The findings suggest that different frequencies and functions of compliments between the two speakers construct multiple identities differently for them in terms of gender, ethnicity, and host-guest relationships. The paper discusses what EFL speakers should be aware of to use compliments and related features as part of the pragmatic competence that will enable their participation in intercultural communication by constructing their preferred identities.
\end{abstract}

Index Terms-Compliments, EFL, intercultural communication, politeness, self-denigration.

\section{INTRODUCTION}

From a social constructionist viewpoint, identity is performance and is not pre-given [1], [2]. Identities are constructed by individual speakers through their socialization processes in various communities of practice including family, school, and workplace. As they participate in these communities and interact with other members, they acquire a range of social roles, behaviors, and linguistic practices they use to construct their identities in specific contexts. Conversation is viewed as one of the most important sites for such identity construction [3], [4].

A number of empirical studies of learner interactions have reported that non-native speakers of English use speech acts differently from native speakers. For example, EFL learners with different cultural backgrounds use speech acts of apology, complaint, and refusals differently from native speakers of English with respect to frequency, semantic formulas, and directness [5]. Such differences can have negative consequences, such as seeing their behavior or even personality judged impolite [6].

This study focuses on the speech act of compliments used in English conversations between non-native speakers of English. Given the ever-increasing number of such speakers among students who go abroad on exchange programs [7], interaction among them is important and therefore worth investigating. Drawing on theoretical approaches and methods from pragmatics, the paper analyses the speech act of compliments in L2 English conversations between a Chinese

Manuscript received September 1, 2016; revised March 3, 2017.

Hiroko Itakura is with the Hong Kong Baptist University, Hong Kong (e-mail: Hiroko@hkbu.edu.hk). male and a Swedish male and explores how their use may construct and convey different identities between individual speakers.

\section{COMPLIMENTS}

Compliments have often been discussed in relation to politeness and gender. Politeness can be seen as consisting primarily of a set of face-saving strategies speakers decide to adopt by rationally considering their interpersonal goals [8]. According to this view, positive politeness strategies are used to protect speakers' face, that is, their need to be liked and approved of, while negative politeness strategies are used to protect the speakers' need for freedom from imposition. Compliments are thus closely related to positive politeness strategies, while other speech acts such as apologies are linked to negative politeness strategies. While the proponents of this view suggest that this analysis of politeness may be applicable across languages, other scholars have suggested that politeness is in fact culture-specific.

One of the most frequently discussed culture-specific aspects of politeness in relation to compliments is the different levels of importance attached to modesty in Eastern and Western languages. ${ }^{1}$ For example, it has been suggested that while there are no absolute divisions between languages along those lines with regard to basic notions of politeness, modesty and self-denigration (i.e., placing low value on the self's qualities) are more strongly emphasized in Eastern languages such as Chinese, Japanese, and Korean than in Western languages such as English, which tolerates self-praise to a greater extent [9]. Similarly, self-denigration and praise of the other has been described as important features of politeness in Chinese by a number of researchers [10]-[12]. For example,

$\ldots$ it is unquestionable that they [self-denigration and addressee elevation] are actively present in modern Chinese discoursive behavior. In practice, elevation and denigration manifest themselves in the symbolic underestimation of the entities belonging to the speakers and their dependents and the overestimation of the entities belonging to the interlocutors and their dependents [11, p. 138].

A review of a large number of studies of compliment giving $^{2}$ and responding behavior across European and Asian

\footnotetext{
${ }^{1}$ Following researchers who compared politeness phenomena across languages (e.g., [8], [9]), a contrast is made here between Eastern and Western languages. However, an Asian vs. European alternative has been proposed [10]. In this paper, both formulations are adopted.

In this paper, the terms "praise" and "compliment" are used interchangeably to refer to speech acts that express appreciation of attributes valued by both speaker and addressee while giving credit to the addressee (or to the speaker in the case of self-praise) [13].
} 
languages shows that speakers of English and European languages such as German and Spanish tend to accept compliments, whereas East Asian speakers, including Chinese and Japanese speakers, tend to reject them [10].

Another aspect of compliments that has received attention is their relationship to gender [13], [14]. An investigation of the distribution of compliments and of contexts in which they were used among male and female university students in the United States found that women generally give compliments more frequently than men in same-sex talk [14]. However, in goal-oriented contexts such as sports coaching, men give compliments to a similar degree to women. In addition, the topics of compliments were also found to differ, with men complimenting each other's performance, talent, or achievements while women tend to compliment appearance. Moreover, male and female university students in the US differed with regard to responding to compliments. While women were found to avoid accepting compliments or to deflect them, sometimes in a self-degrading manner, probably because they tend to value equality, compliments were often accepted in all-male talk, leading to the construction of a hierarchical relationship between the participants based on individual performance.

\section{THE STUDY}

This research adopts a case study approach [15], [16] in order to examine in detail how the focal speech act of compliments is used in the specific context of intercultural communication. To this end, naturally occurring L2 intercultural conversations between a Chinese male and a Swedish male were chosen in order to address the question of how compliments are used to construct identity in conversations between these two non-native speakers of English.

\section{A. Dataset}

Two all-male L2 English conversations were chosen as the basis of the study. Each conversation lasted approximately one hour. The participants were Carson (a Hong Kong Chinese speaker, aged 23) and Stefan (a Swedish speaker, aged 24). ${ }^{3}$ Their English proficiency was "very good" for both (IELTS scores: 7.5).

At the time of recordings, Stefan was an exchange student on a master's program in business studies at the Hong Kong university where Carson was studying on a master's program in education. Carson was born and raised in Hong Kong and speaks Chinese as his mother tongue. Stefan had spent about two and a half months in Hong Kong at the time of the first recording. They had mutual friends but never had a long conversation prior to the first recording. The second recording took place one week after the first. Both participants were recruited by the author's research assistant and invited to have conversations in English over lunch. ${ }^{4}$ The lunchtime setting was chosen because such conversations capture naturalistic interactions and can create ideal

\footnotetext{
${ }^{3}$ All names are pseudonyms.

${ }^{4}$ The participants were paid HK\$150 (or approximately US\$20) each to cover the cost of the meals and as a token of appreciation for their help with the recordings.
}

opportunities for an informal and relaxed exchange [17]. The recorded conversations were lively and frequently accompanied by laughter, jokes, and even occasional swear words. Both speakers were relaxed and seemed to enjoy talking to each other.

\section{FINDINGS}

One of the most salient features of these conversations are the nature, type, and frequency, and responses to compliments. Most of compliments the two speakers exchanged related to each other's country of origin: the host country (Hong Kong), and the guest country (Sweden). No example was found of Carson and Stefan complimenting on each other's talents, achievements, or performance, a feature often associated with all-male talk (as noted above). Frequency counts of instances of compliments were performed by categorizing them into "other-praise" (complimenting the other) and "self-praise" (praising the self). Instances of self-denigration were also quantified as this feature is related to self-/other- evaluation. No cases of criticism of the other were found in the dataset. Table I summarizes the results of the two recordings combined.

TABLE I-1: INSTANCES OF OTHER-EVALUATION

\begin{tabular}{|l|c|c|c|}
\hline \multicolumn{1}{|c|}{} & Other-praise & \multicolumn{2}{c|}{ Other-criticism } \\
\hline Carson & \multicolumn{2}{|c|}{17} & \\
\hline Stefan & \multicolumn{2}{|c|}{0} \\
\hline \multicolumn{4}{|c|}{ TABLE I-2: INSTANCES OF SELF-EVALUATION } \\
\hline & Self-praise & $\begin{array}{c}\text { Self-denigrati } \\
\text { on }\end{array}$ & $\begin{array}{c}\text { Total } \\
\text { (self/other) }\end{array}$ \\
\hline Carson & 6 & 43 & 66 \\
\hline Stefan & 8 & 3 & 24 \\
\hline
\end{tabular}

A noticeable feature is the glaringly unequal distribution of self-denigration between Carson and Stefan. When comparing Hong Kong and Sweden, Carson often refers to Asia and Europe, thus creating an Eastern-Western dichotomy. In addition, Carson denigrates the self, that is, evaluates his country (Hong Kong) negatively more frequently than Stefan gives a negative evaluation of Sweden (43, or $65 \%$, of 66 instances and 3, or $12.5 \%$, of 24 instances, respectively).

1) Technical papers submitted for publication must advance the state of knowledge and must cite relevant prior work.

\section{Excerpt 1}

Carson and Stefan are discussing working conditions in Hong Kong and Sweden. Stefan has just explained that it may be unfair that people who earn more should pay more tax as they have to work long hours.

2) 1 Carson: yeah, yeah. Oh, by the way, Hong Kong is top in the working hours list.

3) 2 Stefan: is it?

4) 3 Carson: I think it's top one or maybe top three (.) in the world. ((Stefan: oh)) Like all Asian countries, like all 
Asian countries, we are top of the list. We are top of the top. ((Stefan: yeah)) In the United States and Hong Kong. It's top of the top.

5) 4 Stefan: that's crazy.

6) 5 Carson: ((laughter)) and that's the reason why we think you know, Europe is so good. Hong Kong people know about Europe is that they always only drink alcohol ((laughter))

[10 turns omitted]

7) 16 Stefan: and you have water at home. And I think people are nice here.

8) 17 Carson: I think it's the people we have, like the most difference

9) 18 Stefan: yeah.

10) 19 Carson: and I guess you know they have better air there. You know air pollution in Hong Kong. ((Stefan: yeah))

11) 20 Stefan: that's so true, and we have a lot of space. That's the huge difference ((Carson: yeah)) yeah you are the one who told me that Europe has so much space.

12) 21 Carson: yeah! So much space. We have so little in Hong Kong. ((Stefan: yeah)) I was talking with my Hong Kong friend who moved to Australia for a few years already. We were like talking about a flat or buying a house in Hong Kong and in Australia. And for the same price, like maybe three million Hong Kong dollars, you will get a small flat in Hong Kong and then you will get a house in Australia. ((Stefan: yeah)) Like two-story house.

13) 22 Stefan: yeah, but I think this is the same in Sweden. ((Carson: oh)) I mean for three thousand Hong Kong dollar (1.5), we will not get a big house but you can get a house.

14) 23 Carson: this is really frustrating ((laughter))

15) 24 Stefan: yeah.

As can be seen in this excerpt, Stefan praises the other, here the host country, Hong Kong, without comparing it to his own either positively or negatively (e.g., "I think people are nice here" in Turn 16). By contrast, Carson's other-praise of the guest's country (Sweden) is given in conjunction with his self-denigration of Hong Kong, essentially as "Sweden is good and Hong Kong is bad." When Carson compliments Sweden (commenting, for example, that "they have better air there" in Turn 19, Carson denigrates Hong Kong in the same turn as "You know air pollution in Hong Kong [is bad]." Similarly, Carson initiates his self-denigration of Hong Kong accompanied with his other-praise of Sweden, invoking the dichotomy whereby "Sweden is good and Hong Kong is bad." For example, in Turn 3, he says: "We are top of the top (in terms of long working hours)" and then moves on to complimenting Sweden ("Europe is good" in Turn 5). Carson's use of other-praise and self-denigration thus follows closely the politeness norm of "praise other, denigrates self" associated with Eastern languages such as Chinese [9]. Moreover, Carson's response to compliments given by Stefan also indicates his greater tendency to self-denigrate compared to Stefan. Table II summarizes these results:

As illustrated in Tables II-1 and II-2, no instance was found of Carson directly accepting praise given by Stefan. Rather, his acceptance is accompanied by hedging or downgrading (see how Carson accepts Stefan's praise of Hong Kong for having "nice people" in Turn 17 but then downgrades it by bringing in the negative aspect of air pollution in Turn 19.). Overall, Stefan accepts compliments of his own country to a greater degree than Carson.

TABLE II-1: RESPONSE TO OTHER PRAISE: “ACCEPTANCE”

\begin{tabular}{|l|c|c|}
\hline & $\begin{array}{l}\text { Acceptance without } \\
\text { mitigation }\end{array}$ & Mitigated acceptance \\
\hline Carson & 0 & 5 \\
\hline Stefan & 8 & 0 \\
\hline
\end{tabular}

TABLE II-2: RESPONSE TO OTHER PRAISE: "NON-ACCEPTANCE"

\begin{tabular}{|c|c|c|c|}
\hline & Rejection & $\begin{array}{c}\text { No explicit } \\
\text { response }\end{array}$ & Total \\
\hline Carson & 1 & 9 & 15 \\
\hline Stefan & 2 & 7 & 17 \\
\hline
\end{tabular}

\section{DISCUSSION AND CONCLUSION}

The findings show that the distribution of compliments in L2 English conversations between a Chinese male and a Swedish male was uneven. The most noticeable difference was that self-denigration was used much more frequently by the Chinese male than by the Swedish male. Unlike previous studies of compliments in all-male conversations, most compliments in this dataset related to each other's country. This feature may be instrumental in constructing different identities for the two speakers.

First, the frequent use of self-denigration by Carson follows closely the Asian norm of politeness that requires speakers to praise the other and denigrate the self [9]-[11]. This may therefore help construct Carson's identity as an Eastern or Asian speaker. In addition, his constant invoking of an exaggerated self/other, "Hong Kong bad, Sweden good" dichotomy may be related to the host-guest relationship to the extent that speaking negatively of insiders (hosts) and highly of outsiders (guests) is often claimed to be a characteristic of norms of politeness in Eastern languages. Second, Carson's frequent rejection of compliments may also convey a degree of femininity (see above). Therefore, his compliments convey multiple identities in relation to ethnicity, gender, and host status all at once. On the other hand, Stefan's more frequent use of praising the self (his own country), avoidance of self-denigration, and acceptance of compliments paid to Sweden may convey a more assertive and possibly more masculine identity.

The findings suggest that it is important for Asian male EFL speakers to be aware of the possibility that by adhering to Asian politeness norms as they relate to compliments, they may convey an overly humble identity, even a degree of femininity, which may have unintended consequences in the form of being perceived negatively [18], including coming across as powerless. It may therefore be useful to help EFL learners become aware of different ways of using compliments and related speech acts, including accepting or deflecting compliments, the potential effects of 
self-denigration, and the possible influence of their use of such strategies on how their identities are constructed by other participants who may not share similar norms of politeness in their own L1. For this purpose, using transcripts of spontaneous talk of the kind analyzed in this study may be useful as a basis for class discussions and overt teaching as they are laden with a range of relevant politeness features along with their associated linguistic expression. Such awareness training should aim to enable EFL students to predict the consequences of any modifications to their use of such strategies and thus make informed decisions as to whether they should follow L1 cultural norms of politeness and gender or adapt - or even ignore - these and thus construct or maintain their preferred identities.

\section{APPENDIX: TRANSCRIPTION CONVENTIONS}

(.) Short pause (less than 1 second)

(2.0)Longer pause (in seconds)

- Incomplete utterance

: Lengthened vowel

[...] Element(s) supplied by the author to facilitate interpretation of relevant utterance

\section{ACKNOWLEDGEMENT}

I am indebted to Carson and Stefan for participating in the recordings. I am also grateful to participants in the $17^{\text {th }}$ annual conference of the Pragmatics Society of Japan, Kyoto, November 2014, for their feedback on earlier versions of this paper.

\section{REFERENCES}

[1] J. Butler, Gender Trouble: Feminism and the Subversion of Identity, New York: Routledge, 1999.

[2] P. Eckert and S. McConnell-Ginet, Language and Gender, 2nd ed. Cambridge: Cambridge University Press, 2013.

[3] M. Bamberg, "Stories, Big or Small: Why Do We Care?" Narrative Inquiry, vol. 16, no. 1, pp. 139-147, 2006.
[4] J. Holmes, "Storytelling in New Zealand women's and men's talk," in Gender and Discourse, R. Wodak, Ed. London: Sage, 1997, pp. 263-293.

[5] K. Bardovi-Harlig, "Evaluating the empirical evidence: Grounds for instruction in pragmatics?" in Pragmatics in Language Teaching, $\mathrm{K}$. R. Rose, and G. Kasper, Eds. Cambridge: Cambridge University Press, 2001, pp. 13-23.

[6] J. Thomas, "Cross-cultural pragmatic failure," Applied Linguistics, no. 2, pp. 91-112, 1983.

[7] J. Jackson, "Education Abroad," in The Routledge Handbook of Language and Intercultural Communication, J. Jackson, Ed. London: Routledge, 2012, pp. 449-463.

[8] P. Brown and S. Levinson, Politeness, Cambridge: Cambridge University Press, 1987.

[9] G. Leech, "Politeness: Is there an east-west divide?" Journal of Politeness Research, vol. 3, pp. 167-206, 2007.

[10] R. Chen, "Compliment and compliment response research," in Pragmatics across Languages and Cultures, A. Trosborg, Ed. Berlin: De Gruyter Mouton, 2010, pp. 79-102.

[11] D. Z. Kádár and Y. Pan, "Politeness in China," in Politeness in East Asia, D. Z. Kádár and Y. Pan, Eds. Cambridge: Cambridge University Press, 2011, 125-146.

[12] H. Spencer-Oatey and P. Ng, "Reconsidering Chinese modesty: Hong Kong and mainland Chinese evaluative judgments of compliment responses," Journal of Asian Pacific Communication, vol. 11, no. 2, pp. 181-201, 2002.

[13] J. Holmes, "Paying compliments: A Sex-preferential Politeness Strategy," Journal of Pragmatics, vol. 12, pp. 445-465, 1988.

[14] J. Rees-Miller, "Compliments revisited: Contemporary compliments and gender," Journal of Pragmatics, vol. 43, 2673-2688, 2001.

[15] M. Denscombe, The Good Research Guide for Small-scale Social Research Projects, Milton Keynes: Open University Press, 2004.

[16] B. Flyvbjerg, "Five misunderstandings about case study research," in Qualitative Research Practice, C. Scale, G. Gobo, J. F. Gubrium, and D. Silverman, Eds. London: Sage, 2004, pp. 420-434.

[17] C. B. Leung, "Collaborative narration in preadolescent girl talk: A Saturday luncheon conversation among three friends," Journal of Pragmatics, vol. 41, 1341-1357, 2009.

[18] L. Yates, "Pragmatic challenges for second language learners," in Pragmatics Across Languages and Cultures, A. Trosborg, Ed. Berlin: De Gruyter Mouton, 2010, pp. 287-308.

Hiroko Itakura has research interests in the areas of gender and language, intercultural communication, pragmatics, and discourse analysis. She is the author of Conversational Dominance and Gender (John Benjamins, 2001) and has published articles in Journal of Pragmatics, Journal of Multilingual and Multicultural Development, Language in Society, Language, Culture, and Curriculum, Pragmatics, and Pragmatics and Society. 